\title{
B-N Codoped p Type ZnO Thin Films for Optoelectronic Applications
}

\author{
Nripasree Narayanan ${ }^{a}$, Nangarath Kannoth Deepak ${ }^{a *}$ \\ ${ }^{a}$ Department of Physics, School of Pure \& Applied Physics, Kannur University, Payyanur Campus, \\ Kannur, Kerala, India
}

Received: July 05, 2017; Revised: October 13, 2017; Accepted: October 25, 2017

\begin{abstract}
The success of codoping by donor-acceptor impurities in accomplishing $\mathrm{p}$ type $\mathrm{ZnO}$ thin films deposited by spray pyrolysis technique is reported here. Monodoping $\mathrm{ZnO}$ with $\mathrm{N}$ altered the conductivity type but the resistivity is too high making it practically impossible to be useful in optoelectronic applications. B-N codoping increased the carrier concentration and obtained comparatively low resistivity because codoping enhanced the acceptor incorporation by forming acceptor-donor-acceptor complex in the band gap. XRD analysis revealed the dependence of dopant incorporation on the texture and microstructure of the films. XPS analysis confirmed the enhancement of N incorporation with codoping. Energy gap value increased for codoped films due to the Burstein-Moss effect, arising from the increase in carrier concentration. Hence the present work envisages the preparation of transparent $\mathrm{p}$ type $\mathrm{ZnO}$ thin films suitable for tandem thin film solar cells and also for other optoelectronic applications.
\end{abstract}

Keywords: $Z n O, B-N$ codoping, p type, Burstein-Moss effect, tandem thin film solar cells.

\section{Introduction}

Transparent conducting oxides (TCOs) are a unique class of materials with wide energy band gap and tunable electrical conductivity from insulating via semiconducting to conducting. This blending of the two conjugate properties optical transparency and high electrical conductivity - made thin films of these materials suitable for modern device applications like thin film solar cells ${ }^{1}$, optical waveguides ${ }^{2}$, light emitting diodes ${ }^{3}$, thin film transistors ${ }^{4}$, gas sensors ${ }^{5}$, etc. Because of low-cost, abundance, less-toxicity and biocompatibility, materials researchers prefer zinc oxide $(\mathrm{ZnO})$ as the most prominent candidate. In addition, the optical energy gap and electrical conductivity of $\mathrm{ZnO}$ can be modified respectively by alloying or doping with suitable materials.

$\mathrm{ZnO}$ is intrinsically $\mathrm{n}$ type semiconductor (energy gap $\sim 3.37 \mathrm{eV}$ ) due to the presence of zinc interstitials or oxygen vacancies and is not amenable to both types doping and thus it is harder to develop $\mathrm{p}$ type $\mathrm{ZnO}$. This is mainly due to problems such as its self compensating effect, deep acceptor levels and low solubility of acceptor dopants ${ }^{6}$. Codoping of $\mathrm{ZnO}$ with group III and group $\mathrm{V}$ elements can be utilized to improve the acceptor solubility and thereby making acceptor levels shallower ${ }^{7}$. A few reports are available in the literature studying the feasibility of Al-N codoping ${ }^{8}$, In-N codoping ${ }^{9-11}$, B-N codoping ${ }^{12}$, Ga-N codoping ${ }^{13}, \mathrm{Ag}-\mathrm{N}$ codoping $^{14}, \mathrm{Sn}-\mathrm{N}$ codoping ${ }^{15}$ etc. in order to improve the $\mathrm{p}$ type electrical performance of $\mathrm{ZnO}$ thin films. Thus in the present study we propose the deposition of B-N codoped

*e-mail: dr.deepaknk@yahoo.com $\mathrm{p}$ type thin films of $\mathrm{ZnO}$ by spray pyrolysis to be useful in the field of optoelectronics. In tandem thin film solar cells, the efficiency can be improved by stacking absorbers with different energy gap to utilize the entire solar spectrum. But the main problem associated with this is the requirement of interconnecting contacts of both $\mathrm{n}$ and $\mathrm{p}$ types, highly transparent to lower energy photons. Thus in the present study, we tried to develop highly transparent and conducting $\mathrm{p}$ type $\mathrm{ZnO}$ thin films. To accomplish $\mathrm{p}$ type electrical conductivity, $\mathrm{ZnO}$ thin films were codoped with boron (B) and nitrogen $(\mathrm{N})$. Among the various deposition techniques, we opted chemical spray pyrolysis because of its easiness in accomplishing doping during the preparation of precursor solution by simply adding the salts of the desired dopant. In spray deposition, there is no need of vacuum at any stage of preparation and is feasible for large area deposition. Moreover, it is simple, low cost and versatile.

\section{Materials and Methods}

$\mathrm{B}-\mathrm{N}$ codoped $\mathrm{ZnO}$ thin films with varying $\mathrm{B}$ concentration ( 0 - 4 at $\%$ ) were deposited on glass substrates by spray pyrolysis method. Prior to film deposition, the substrates were cleaned in solutions of diluted chromic acid, sodium hydroxide and acetone followed by ultrasonic bath cleaning with hot distilled water. Zinc acetate dihydrate $\left[\mathrm{Zn}\left(\mathrm{CH}_{3} \mathrm{COO}\right)_{2}\right.$ $\left.2 \mathrm{H}_{2} \mathrm{O}\right]$, ammonium acetate $\left[\mathrm{NH}_{4} \mathrm{C}_{2} \mathrm{H}_{3} \mathrm{O}_{2}\right]$ and boric acid $\left[\mathrm{H}_{3} \mathrm{BO}_{3}\right]$ were used as the sources of $\mathrm{Zn}, \mathrm{N}$ and $\mathrm{B}$ respectively. A mixture of methanol, deionized water and acetic acid taken in the proportion 65:30:5 plays the role of solvent for the preparation of stock solution. Concentration of the precursor solution was kept fixed at $0.4 \mathrm{M}$ and the $\mathrm{N}: \mathrm{Zn}$ proportion of 
2:1 was maintained for all the samples while the B doping concentration was varied from $0-4$ at $\%$. In our previous study $^{16}$, we investigated the impact of $\mathrm{N}$ doping with different $\mathrm{N} / \mathrm{Zn}$ ratio $(0-3)$ on the various physical properties of $\mathrm{ZnO}$ thin films deposited on glass substrates by spray pyrolysis technique and optimized the $\mathrm{N}: \mathrm{Zn}$ ratio as $2: 1$ because that particular sample possessed better optoelectronic properties compared to others. So we extended the investigation by fixing the particular doping percentage for $\mathrm{N}$ salt and tried to improve the acceptor solubility by adding donor dopants also at different concentrations. Equivalent masses of relevant salts were added to the solvent to achieve the desired composition and the resulting solutions were then continuously stirred with a hot magnetic stirrer for 30 minutes at a temperature of about $60^{\circ} \mathrm{C}$. After filtering, these solutions were sprayed over the glass substrates which were kept on a hot plate maintained at $400 \pm 10^{\circ} \mathrm{C}$ to obtain B-N codoped $\mathrm{ZnO}$ thin films.

The structural mapping of the as-deposited films were done by using Rigaku Miniflex 600 X-ray Diffractometer with $\mathrm{CuK}_{\alpha}$ radiation of wavelength, $\lambda=1.5406 \AA$. The morphological and composition analyses were performed with JEOL Model JSM - 6390 scanning electron microscope operated at $20 \mathrm{keV}$. The elemental composition analysis was carried out using X-ray photoelectron spectroscopy (Thermo Fisher Scientific). The optical transmission measurement was done with Jasco V-650 double beam spectrophotometer. The spectra were recorded in the $300-900 \mathrm{~nm}$ spectral region. The electrical properties were measured by the Van der Pauw method using the Hall measurement system (Ecopia Hall Effect Measurement System) with a magnetic field strength of $0.55 \mathrm{~T}$ at room temperature. For the measurement, we prepared $1 \mathrm{~cm} \times 1 \mathrm{~cm}$ samples and the contacts were made at the four corners of each sample. Highly conducting silver paste was used to make ohmic contacts at the four corners in the Van der Pauw geometry. These contacts were then properly heated and allowed to dry to carry out electrical characterization. Thickness of the deposited films was determined by the gravimetric method (Schimadzu AY 220 Model Balance) and also by using Stylus Profilometer (Dektak 150).

\section{Results and Discussion}

\subsection{Structural properties}

XRD pattern of the prepared thin films were shown in Fig. 1. The samples have no deviation from the hexagonal wurtzite geometry (JCPDS Card No. 36-1451) so that these films are monophasic indicating successful incorporation of dopants in the $\mathrm{ZnO}$ host lattice. Film with 0 at \% B (N monodoped) showed a preferential orientation along the (100) plane with diminutive grain growth along (002), (101) and (110) planes. But B-N codoping shifted the preferred orientation along the $\mathrm{c}$ axis, (002) plane normal to the substrate surface. This shift in preferential orientation is related to the inclusion of new impurities. Up to 3 at $\%$ B doping, the films exhibited extremely strong preferential orientation along the (002) plane while for 4 at\% B doped film, (101), (102) and (103) reflections appeared with comparable intensity in addition to the preferred orientation so that it is highly polycrystalline. Thus further increase in doping percentage may result in highly polycrystalline or even amorphous materials.

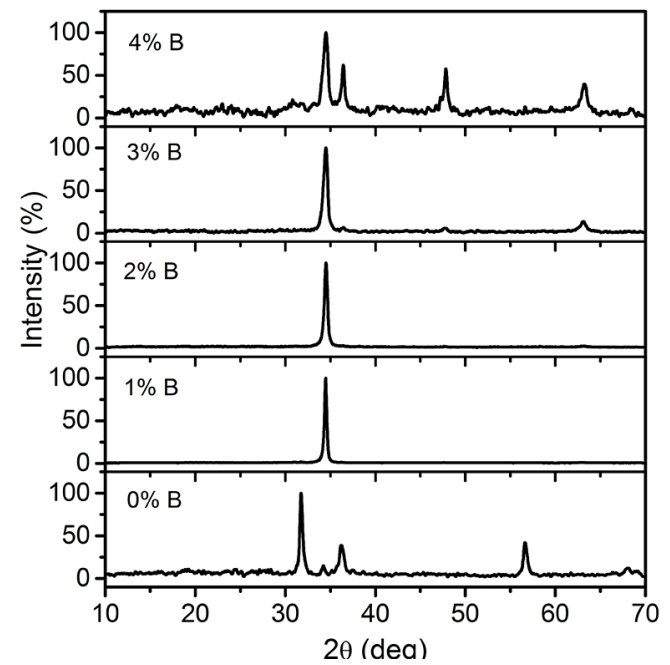

Figure 1. XRD pattern of the spray pyrolysed B-N codoped $\mathrm{ZnO}$ thin films with various B concentrations.

Crystallite size of the prepared samples for the most intense diffraction peak was calculated using the Scherrer formula ${ }^{17}$

$$
D=\frac{0.9 \lambda}{\beta \cos \theta}
$$

where 0.9 is the value of the shape factor, $\lambda(=1.5406 \AA)$ is the wavelength of the X-rays used, $\beta$ is the full-width at half maximum intensity in radians and $\theta$ is the Bragg's angle. The dislocation density $(\delta)$ which is a measure of defects in the films can be calculated using the formula given below ${ }^{18}$

$$
\delta=\frac{1}{D^{2}}
$$

The calculated values of crystallite size and dislocation density are presented in Table 1 . It is clear that all the films were nano-structured. The crystallite size increased up to 2 at $\%$ B-N codoping and then decreased. The improvement in crystallinity could be due to the highly textured growth of films along the (002) plane having minimum surface energy of formation. The deterioration in crystallinity with further increase in B concentration which favoured random growth of crystallites may arise from the defects and disorders 
Table 1. Structural parameters including crystallite size (D), dislocation density $(\delta)$, micro-strain $(\varepsilon)$, lattice parameters (a and c), unit cell volume $(\mathrm{V})$, internal relaxation parameter $(\mathrm{u})$ and bond length $\left(\mathrm{b}_{1}\right)$ of $\mathrm{B}-\mathrm{N}$ codoped $\mathrm{ZnO}$ thin films with various $\mathrm{B}$ concentrations.

\begin{tabular}{ccccccccc}
\hline $\begin{array}{c}\text { B Concentration } \\
(\%)\end{array}$ & $\mathrm{D}(\mathrm{nm})$ & $\delta\left(\times 10^{15} \mathrm{~m}^{-2}\right)$ & $\varepsilon\left(\times 10^{-3}\right)$ & $\mathrm{a}(\AA)$ & $\mathrm{c}(\AA)$ & $\mathrm{V}\left(\times 10^{-30} \mathrm{~m}^{3}\right)$ & $\mathrm{u}$ & $\mathrm{b}_{1}(\AA)$ \\
\hline 0 & 20.91 & 2.28 & 6.06 & 3.2507 & 5.2364 & 47.92 & 0.378 & 1.98 \\
1 & 27.73 & 1.30 & 4.22 & 3.2266 & 5.1981 & 46.85 & 0.378 & 1.96 \\
2 & 31.99 & 0.98 & 3.65 & 3.2212 & 5.1923 & 46.66 & 0.378 & 1.96 \\
3 & 15.18 & 4.34 & 7.69 & 3.2297 & 5.1923 & 46.90 & 0.379 & 1.97 \\
4 & 11.63 & 7.39 & 10.04 & 3.2306 & 5.1923 & 46.93 & 0.379 & 1.97 \\
\hline
\end{tabular}

introduced by the dopants in the $\mathrm{ZnO}$ structure by segregating into the non-crystalline region at the grain boundaries ${ }^{19}$. Also the observed variation in crystallinity may arise from the strain suffered by the lattice. The micro-strain developed in the film was evaluated using the relation ${ }^{20}$

$$
\varepsilon=\frac{\beta}{4 \tan \theta}
$$

The calculated values of strain are presented in Table 1 and show a negative correlation with the crystalline size. The lattice parameters (a and c) and unit cell volume (V) for the hexagonal structure can be determined using the relations ${ }^{21}$

$$
\begin{gathered}
\frac{1}{d_{(h k l)}^{2}}=\frac{4}{3}\left[\frac{h^{2}+h k+k^{2}}{a^{2}}\right]+\frac{l^{2}}{c^{2}} \\
V=\frac{\sqrt{3}}{2} a^{2} c
\end{gathered}
$$

The calculated values of a, c and $\mathrm{V}$ are summarized in Table 1. Compared to $\mathrm{N}$ monodoped $\mathrm{ZnO}$ thin film, the lattice parameters and unit cell volume decreased due to the successful incorporation of $\mathrm{N}$ with lower ionic radius at $\mathrm{O}$ sites. The internal relaxation parameter $(\mathrm{u})$ and the bond length $\left(b_{1}\right)$ were calculated using the following relations ${ }^{22}$

$$
u=\frac{1}{3}\left(\frac{a^{2}}{c^{2}}\right)+\frac{1}{4}
$$

and

$$
b_{l}=c u
$$

and are summarized in Table 1. The internal relaxation parameter is a measure of the amount by which each atom is displaced with respect to the next along the $c$-axis and is 0.375 for an ideal wurtzite crystal. From the table we can conclude that in the deposited films, the atoms are displaced from the ideal configuration due to the addition of impurities. $\mathrm{B}-\mathrm{N}$ codoping resulted in decrease in bond length compared to monodoped one due to the incorporation of $\mathrm{N}$ at $\mathrm{O}$ sites. Also the calculated values of bond lengths are a little longer than the ideal value ( $1.93 \AA$ ) which could be due to the strain suffered by the lattice. Also we can see from the table that the unit cell volume got reduced for B-N codoped films.

\subsection{Morphological analysis}

Scanning microscope (SEM) images of the as-deposited thin films are shown in Fig.2. The micrographs showed that all the films had grown uniformly over the substrate surface without any irregularities. Also the images concluded the polycrystalline character of the films.

\subsection{X-ray photoelectron spectra (XPS) analysis}

The XPS analysis results for B-N codoped films are shown in Fig. 3 and the respective chemical composition of various elements are presented in Table 2 . The $\mathrm{Zn} 2 \mathrm{p}$ and $\mathrm{O}$ 1s core level spectra were similar for all the samples (not shown here). $\mathrm{Zn} 2 \mathrm{p}$ spectra comprises two peaks located around $1020 \mathrm{eV}$ and $1040 \mathrm{eV}$ corresponding to $2 \mathrm{p}_{3 / 2}$ and $2 \mathrm{p}_{1 / 2}$ states respectively. The $\mathrm{O} 1 \mathrm{~s}$ peak is centred at around $530 \mathrm{eV}$. The N1s XPS core level spectra of all the five samples showed broad peak between $375 \mathrm{eV}$ and $430 \mathrm{eV}$ binding energy. The deconvolution of the signals using Gaussian function gives two different peaks. The peaks with lower binding energy are due to the formation of $\mathrm{N}_{\mathrm{O}}-\mathrm{Zn}$ bond ${ }^{23}$. The higher binding energy peak is the characteristic of $\mathrm{N}_{2}$ species occupied at oxygen vacancies ${ }^{24}$. According to Ozgur et $\mathrm{al}^{25}, \mathrm{~N}_{\mathrm{O}}$ defects behave as shallow acceptors while $\mathrm{N}_{2 \mathrm{O}}$ as double donor. Thus the balance between these two defects determines the nature of conductivity in $\mathrm{ZnO}$ thin films. The peak centred near $190 \mathrm{eV}$ indicates the presence of $\mathrm{B}-\mathrm{N}$ bonds ${ }^{26}$. This peak is not seen in the monodoped film's XPS. Thus the observed enhancement of electrical conductivity can be considered as the consequence of acceptor-donor pair codoping.

\subsection{Optical properties}

In order to qualify as a transparent conductor, the films must possess good optical characteristics. Figure 4 shows the optical transmittance spectra of the as-deposited B-N codoped $\mathrm{ZnO}$ thin films. The films, except the $\mathrm{N}$ monodoped one, exhibited better optical transmission in the visible and NIR region. Also all the samples showed sharp fundamental absorption in the near ultraviolet region and undergone a blue-shift of absorption edge with codoping indicating a band gap broadening. In the high transmittance region, the films showed oscillatory character due to the interference of light between the top and bottom surfaces of the film. Larger the amplitude of oscillation, the larger will be the 

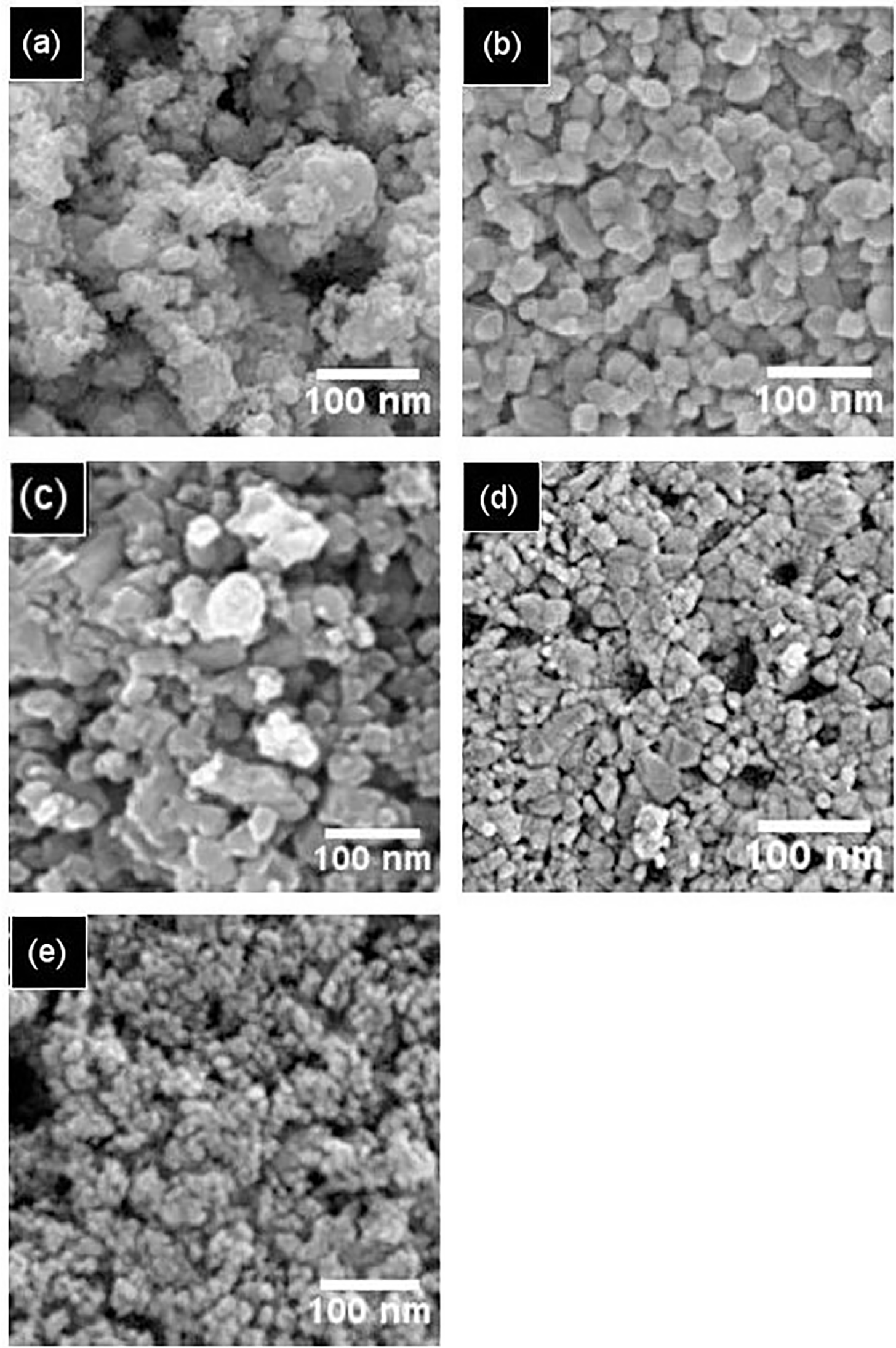

Figure 2. (a-e) SEM images of B-N codoped $\mathrm{ZnO}$ thin films with 0 - 4 at $\% \mathrm{~B}$. 

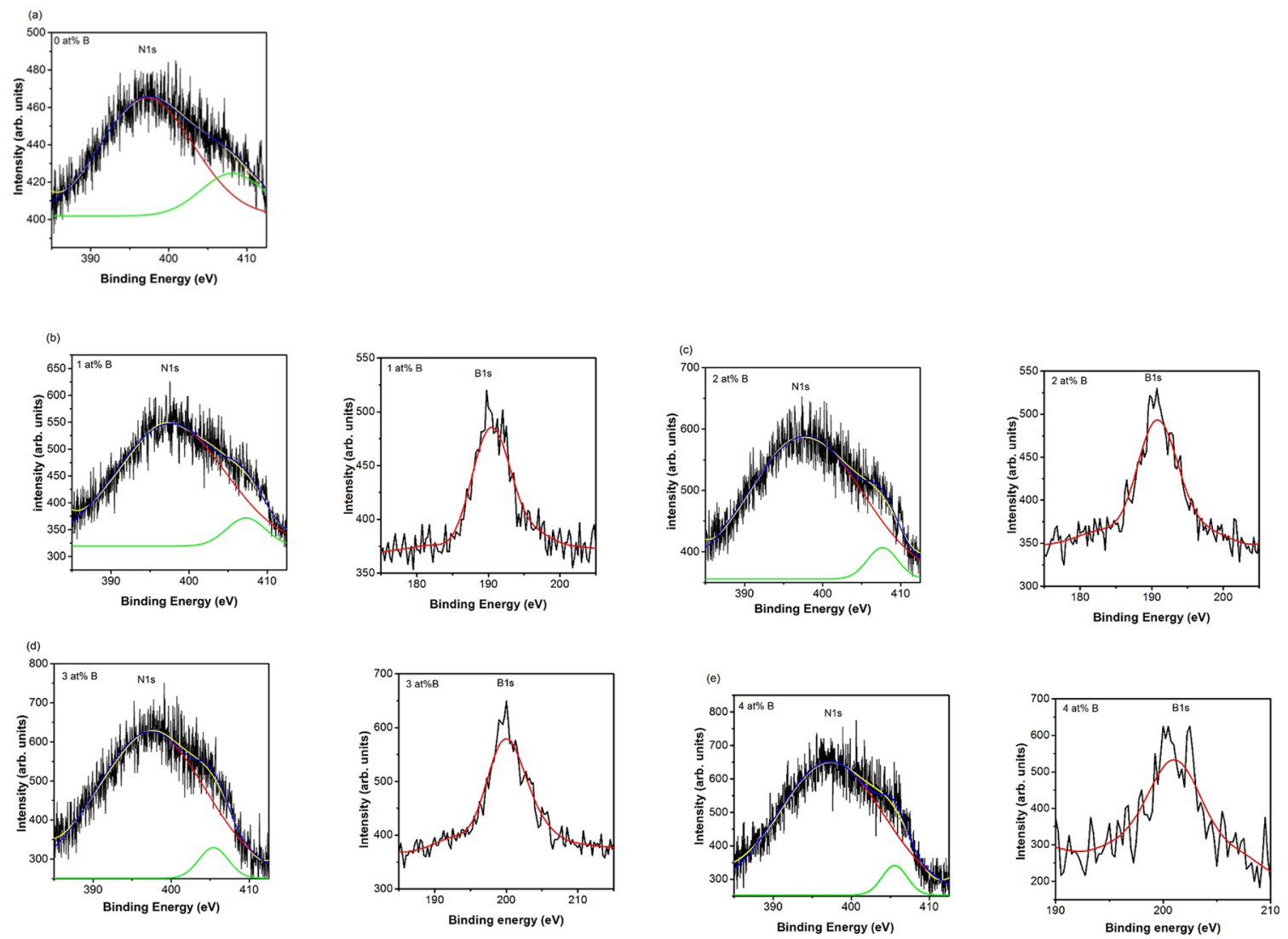

Figure 3. Core level x-ray photoelectron spectra of $\mathrm{N} 1 \mathrm{~s}$ and $\mathrm{B} 1 \mathrm{~s}$ states of $\mathrm{B}-\mathrm{N}$ codoped $\mathrm{ZnO}$ thin films with (a) 0 , (b) 1 , (c) 2 , (d) 3 and (e) 4 at $\%$ B.

Table 2. Results of XPS analysis

\begin{tabular}{|c|c|c|c|c|}
\hline B Concentration (\%) & $\mathrm{Zn}(\mathrm{at} \%)$ & $\mathrm{O}(\mathrm{at} \%)$ & $\mathrm{N}(\mathrm{at} \%)$ & B (at $\%)$ \\
\hline 0 & 53.24 & 40.57 & 6.19 & 0 \\
\hline 1 & 52.84 & 33.58 & 13.58 & 0.38 \\
\hline 2 & 52.18 & 32.67 & 14.24 & 0.91 \\
\hline 3 & 53.47 & 29.98 & 15.41 & 1.14 \\
\hline 4 & 53.18 & 29.35 & 15.64 & 1.83 \\
\hline
\end{tabular}

films' surface smoothness. Thus N monodoped film's surface is less smooth and hence lead to increased scattering of photons from the surface itself and poor optical transmittance. In the case of codoped $p$ type films, there is no significant variation in average transmittance. The film thickness and refractive index at $633 \mathrm{~nm}$ are electronically generated using PARAV software ${ }^{27}$ and were presented in Table 3 along with the experimentally determined thickness values. It can be inferred from the optical transmittance spectra and thickness measurements that the number of peaks and troughs are less for the comparatively thicker ( 2 and 4 at $\%$ B doped) films. This is because more peaks and troughs will appear for thicker films in the higher wavelength region.

Optical band gaps $\left(\mathrm{E}_{\mathrm{g}}\right)$ of the deposited thin films are calculated using the Tauc relation ${ }^{28}$

$$
\alpha=\frac{B}{h v}\left(h v-E_{g}\right)^{n}
$$

where $\alpha$ is the absorption coefficient, hv energy of photon, $\mathrm{B}$ is the band tailing parameter and $\mathrm{n}$ is a constant equal to $1 / 2$ as $\mathrm{ZnO}$ is a direct band material. The plots of $(\alpha h v)^{2}$ versus (hv) for the films were shown in Fig. 5. From the figure, we can make a conclusion that the films are of direct band gap since the plots are linear near the absorption edge. The band gap energies were determined by extrapolating the linear portion of the graph and finding the intercepts on the energy axis. The calculated values of energy gap are presented in Table 3.

The estimated band gap of $\mathrm{N}$ doped $\mathrm{ZnO}$ thin film is $3.269 \mathrm{eV}$. With B-N codoping, the energy gap blue-shifted which 


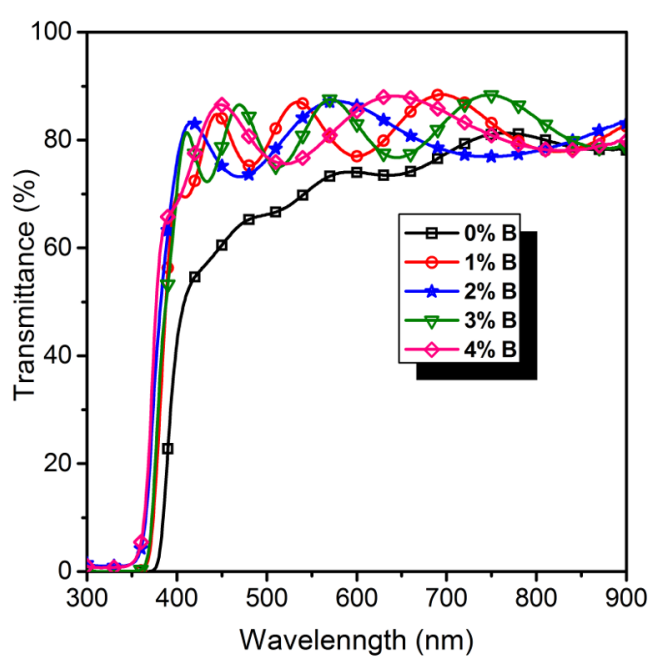

Figure 4. Optical transmittance spectra of the B-N codoped $\mathrm{ZnO}$ thin films deposited by spray pyrolysis technique with various B concentrations.

might be due to the increase in carrier (hole) concentration known as Burstein-Moss effect. The reduced band gap energy for the monodoped $\mathrm{ZnO}$ is due to the incorporation of $\mathrm{N}$ atoms in the $\mathrm{ZnO}$ lattice which cause merging of impurity band with the valence band ${ }^{8}$ and is in agreement with earlier reports ${ }^{29}$. The magnitude of Burstein-Moss energy shift arising from the shift of Fermi levels for the samples were calculated and presented in Table 3.

\subsection{Electrical properties}

Various electrical parameters such as carrier type, carrier concentration, mobility and resistivity of the deposited thin films obtained from Hall measurement are presented in Table 4 along with the measurements made after 20 days of preparation. All the films exhibited $\mathrm{p}$ type electrical conductivity provided by the formation of $\mathrm{N}_{\mathrm{O}}$ acceptors at $\mathrm{O}$ lattice sites. With B-N codoping, hole concentration enhanced by two orders of magnitude compared to $\mathrm{N}$ monodoped one and as a result, we obtained a lower resistive $\mathrm{p}$ type material. The enhancement of hole concentration with codoping is related to the incorporation of reactive donor codopant which activates the incorporation of $\mathrm{N}$ at

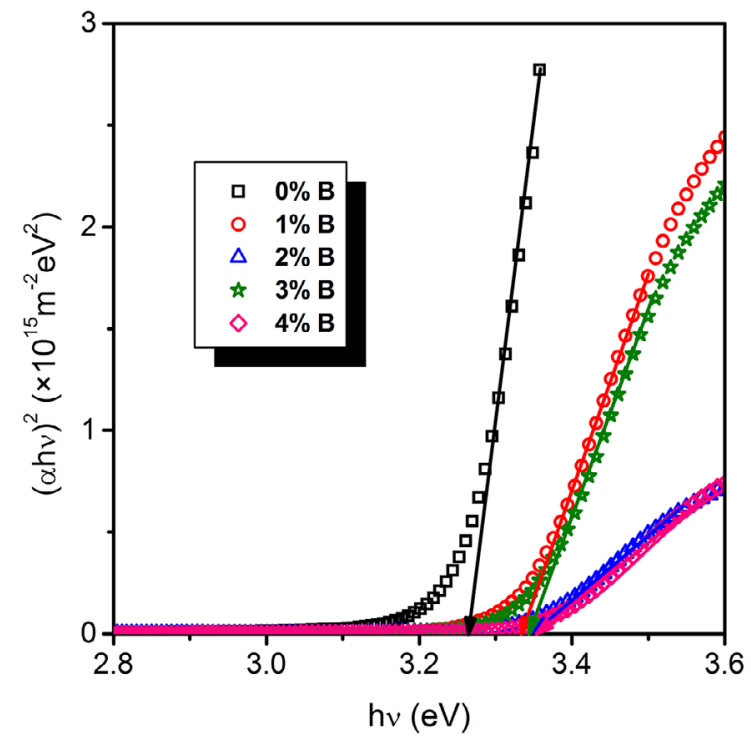

Figure 5. Plot of $(\alpha h v)^{2} v / s$ hv for spray pyrolysed B-N codoped $\mathrm{ZnO}$ thin films with different $\mathrm{B}$ concentration for band gap energy (Eg) determination.

oxygen vacancies by changing the chemical states of $\mathrm{N}^{30}$. Up to 2 at $\%$ B doping the carrier mobility monotonously increased and thereafter started to decrease. The observed trend in carrier mobility with doping might be governed by the scattering at grain boundaries, ionized impurities, other defects etc. Further increase in dopant concentration may sometimes cause the excess dopants to segregate at the grain boundaries where they can be considered as defects due to incomplete bonding. These defects can act as carrier traps which localize the free carriers and form a potential energy barrier. The increase in dopant incorporation increases the barrier heights which prevent the motion of carriers from one crystallite to another and thereby immobilize them. Thus in conclusion, we obtained a lowest resistive or highly conductive $\mathrm{p}$ type $\mathrm{ZnO}$ thin film with $2 \mathrm{at} \% \mathrm{~B}-\mathrm{N}$ codoping. Also the films showed higher stability after 20 days.

$\mathrm{ZnO}$ is a unipolar material which favours $\mathrm{n}$ type doping. Madelung energy, which is the electrostatic contribution to the binding energy of ionic compounds, decreases with donor doping while acceptor doping increases it. But donor-acceptor pair codoping decreases it because the strong acceptor-donor interaction overcomes the repulsive interactions between

Table 3. Estimated values of film thickness $(t)$ by using Profilometer, gravimetric method and using PARAV software, refractive index at $633 \mathrm{~nm}(\mathrm{n})$, Energy gap $\left(\mathrm{E}_{\mathrm{g}}\right)$ and Burstein-Moss energy shift $(\triangle \mathrm{EBM})$ for the thin films of B-N codoped $\mathrm{ZnO}$ with various $\mathrm{B}$ concentrations.

\begin{tabular}{|c|c|c|c|c|c|c|}
\hline \multirow[b]{2}{*}{$\begin{array}{c}\text { Concentration } \\
(\%)\end{array}$} & \multicolumn{3}{|c|}{$\mathrm{t}(\mu \mathrm{m})$} & \multirow[b]{2}{*}{$\mathrm{n}$} & \multirow[b]{2}{*}{$\mathrm{E}_{\mathrm{g}}(\mathrm{eV})$} & \multirow[b]{2}{*}{$\Delta \mathrm{E}_{\mathrm{BM}}(\mathrm{eV})$} \\
\hline & $\begin{array}{c}\text { Stylus } \\
\text { Profilometer }\end{array}$ & Gravimetric & PARAV & & & \\
\hline 0 & 0.421 & 0.394 & 0.357 & 1.973 & 3.269 & 0.011 \\
\hline 1 & 0.357 & 0.371 & 0.328 & 1.935 & 3.336 & 0.265 \\
\hline 2 & 0.408 & 0.419 & 0.372 & 1.970 & 3.347 & 0.796 \\
\hline 3 & 0.417 & 0.399 & 0.363 & 1.910 & 3.343 & 0.829 \\
\hline 4 & 0.410 & 0.413 & 0.368 & 1.992 & 3.366 & 0.842 \\
\hline
\end{tabular}


Table 4. Carrier type, concentration (p), mobility $(\mu)$ and resistivity $(\rho)$ obtained from Hall effect measurement for the thin films of B-N codoped $\mathrm{ZnO}$ with various $\mathrm{B}$ concentrations along with measurements after 20 days.

\begin{tabular}{|c|c|c|c|c|c|}
\hline $\begin{array}{l}\text { Time of } \\
\text { Measurement }\end{array}$ & $\begin{array}{c}\text { B Concentration } \\
(\%)\end{array}$ & Type & $\mathrm{p}\left(\mathrm{cm}^{-3}\right)$ & $\mu\left(\mathrm{cm}^{2} / \mathrm{Vs}\right)$ & $\rho(\Omega \mathrm{cm})$ \\
\hline \multirow{5}{*}{ As-deposited } & 0 & $\mathrm{p}$ & $1.01 \times 10^{16}$ & 6.96 & $8.85 \times 10^{1}$ \\
\hline & 1 & $\mathrm{p}$ & $1.13 \times 10^{18}$ & 10.24 & $5.71 \times 10^{-1}$ \\
\hline & 2 & $\mathrm{p}$ & $5.89 \times 10^{18}$ & 12.86 & $8.54 \times 10^{-2}$ \\
\hline & 3 & $\mathrm{p}$ & $6.27 \times 10^{18}$ & 2.89 & $3.72 \times 10^{-1}$ \\
\hline & 4 & $\mathrm{p}$ & $6.41 \times 10^{18}$ & 1.05 & $9.41 \times 10^{-1}$ \\
\hline \multirow{5}{*}{ After 20 Days } & 0 & $\mathrm{p}$ & $9.41 \times 10^{15}$ & 5.24 & $1.11 \times 10^{2}$ \\
\hline & 1 & $\mathrm{p}$ & $1.04 \times 10^{18}$ & 10.32 & $6.04 \times 10^{-1}$ \\
\hline & 2 & $\mathrm{p}$ & $4.97 \times 10^{18}$ & 12.14 & $1.09 \times 10^{-1}$ \\
\hline & 3 & $\mathrm{p}$ & $5.21 \times 10^{18}$ & 2.45 & $4.92 \times 10^{-1}$ \\
\hline & 4 & $\mathrm{p}$ & $6.57 \times 10^{18}$ & 0.99 & $9.74 \times 10^{-1}$ \\
\hline
\end{tabular}

the acceptors and reduce the Madelung energy and hence ensures the incorporation of acceptors by forming acceptordonor-acceptor complex in the forbidden gap ${ }^{15}$. Thus B-N codoping improves the delocalization of impurity states at the acceptors and stabilizes the ionic charge distribution in the semiconductor. It should be important here that the donor dopant is not the $\mathrm{p}$ type killer, but the reactive codopant which activates acceptors.

\section{Conclusions}

Spray pyrolysis technique is used to deposit thin films of $\mathrm{N}$ monodoped and $\mathrm{B}-\mathrm{N}$ codoped $\mathrm{ZnO}$ with various $\mathrm{B}$ concentrations to achieve good quality $\mathrm{p}$ type thin films. All the films were polycrystalline with hexagonal wurtzite structure and showed no indication of additional phase other than $\mathrm{ZnO}$ and thereby confirmed the mono-phasic nature of the deposited thin films. The optical transmittance of $\mathrm{N}$ monodoped $\mathrm{ZnO}$ thin film was poor while codoped films exhibited better transmission in the Vis-NIR region. With $\mathrm{B}-\mathrm{N}$ codoping, the band gap energy value increased due tothe Burstein-Moss effect. Hall measurement showed that B-N codoping effectively improved the hole concentration and hence the electrical conductivity compared to monodoped film. The enhancement of hole concentration was attributed to the better substitution of $\mathrm{N}$ at $\mathrm{O}$ sites by acceptor-donor pair codoping which was confirmed by the XPS analysis. So we can strongly propose B-N codoping as an effective tool to fulfil the requirements of $\mathrm{p}$ type $\mathrm{ZnO}$ thin films and can be practically used as a transparent interconnect layer in tandem thin film solar cells and also for applications like solid state lighting, photodetectors, thin film transistors, etc.

\section{Acknowledgements}

One of the authors would like to gratefully acknowledge University Grants Commission (UGC), New Delhi, India for providing Senior Research Fellowship (SRF).

\section{References}

1. Chopra KL, Das SR. Thin Film Solar Cells. New York: Springer; 1983.

2. Misra P, Sahoo PK, Tripathi P, Kulkarni VN, Nandedkar RV, Kukreja LM. Sequential pulsed laser deposition of $\mathrm{Cd}_{\mathrm{x}} \mathrm{Zn}_{1-\mathrm{x}} \mathrm{O}$ alloy thin films for engineering $\mathrm{ZnO}$ band gap. Applied Physics A. 2004;78(1):37-40.

3. Gao J, Heeger AJ, Lee JY, Kim CY. Soluble polypyrrole as the transparent anode in polymer light-emitting diodes. Synthetic Metals. 1996;82(3):221-223.

4. Norris BJ, Anderson J, Wager JF, Keszler DA. Spin-coated zinc oxide transparent transistors. Journal of Physics D: Applied Physics. 2003;36(20):L105-L107.

5. Paneva R, Gotchev D. Non-linear vibration behaviour of thin multi-layer diaphragms. Sensors and Actuators A: Physical. 1999;72(1):79-87.

6. Bian JM, Li XM, Gao XD, Yu WD, Chen LD. Deposition and electrical properties of $\mathrm{N}$-In codoped p-type $\mathrm{ZnO}$ films by ultrasonic spray pyrolysis. Applied Physics Letters. 2004;84(4):541-543.

7. Yamamoto T, Katayama-Yoshida H. Physics and control of valence states in $\mathrm{ZnO}$ by codoping method. Physica B: Condensed Matter. 2001;302-303:155-162.

8. Lu JG, Ye ZZ, Zhuge F, Zeng YJ, Zhao BH, Zhu LP. p-type conduction in N-Al co-doped $\mathrm{ZnO}$ thin films. Applied Physics Letters. 2004;85(15):3134-3135.

9. Chen LL, Lu JG, Ye ZZ, Lin YM, Zhao BH, Ye YM, et al. p-type behaviour in In- $\mathrm{N}$ codoped $\mathrm{ZnO}$ thin films. Applied Physics Letters. 2005;87(25):252106.

10. Duta M, Mihaiu S, Munteanu C, Anastasescu M, Osiceanu P, Marin A, et al. Properties of In-N codoped p-type ZnO nanorods grown through a two-step chemical route. Applied Surface Science. 2015;344:196-204.

11. Sahu R, Gholap HB, Mounika G, Dileep K, Vishal B, Ghara $\mathrm{S}$, et al. Stable p-type conductivity in B and N co-doped ZnO epitaxial thin film. Physics Status Solidi B. 2016;253(3):504508 . 
12. Shtereva K, Flickyngerova S, Tvarozek V, Novotny I, Kovac $\mathrm{J}$, Vincze A. Characterization of gallium-nitrogen co-doped zinc oxide thin films prepared by RF diode sputtering. Vacuum. 2012;86(6):652-656.

13. Li W, Kong C, Qin G, Ruan H, Fang L. p-Type conductivity and stability of Ag-N codoped $\mathrm{ZnO}$ thin films. Journal of Alloys and Compounds. 2014;609:173-177.

14. Nripasree N, Deepak NK. Structural, optical and electrical properties of $\mathrm{Sn}-\mathrm{N}$ codoped $\mathrm{p}$ type $\mathrm{ZnO}$ thin films prepared by spray pyrolysis technique for diode applications. Materials Science and Engineering: B. 2016;211:121-127.

15. Sahay PP, Tewari S, Nath RK, Jha S, Shamsuddin M. Studies on ac response of zinc oxide pellets. Journal of Materials Science. 2008;43(13):4534-4540.

16. Narayanan N, Deepak NK. Impact of N doping on the physical properties of ZnO thin films. Surface Review and Letters. 2017. DOI: http://dx.doi.org/10.1142/S0218625X1850035X

17. Ravichandran K, Philominathan P. Investigations on microstructural and optical properties of CdS films fabricated by a low-cost, simplified spray technique using perfume atomizer for solar cell applications. Solar Energy. 2008;82(11):1062-1066.

18. Bilgin V, Kose S, Atay F, Akyuz I. The effect of substrate temperature on the structural and some physical properties of ultrasonically sprayed CdS films. Materials Chemistry and Physics. 2005;94(1):103-108.

19. Ben Ayadi Z, El Mir L, Djessas K, Alaya S. The properties of aluminum-doped zinc oxide thin films prepared by rf-magnetron sputtering from nanopowder targets. Materials Science and Engineering: C. 2008;28(5-6):613-617.

20. Klung HP, Alexander LE. X-Ray Diffraction Procedures: For Polycrystalline and Amorphous Materials. $2^{\text {nd }}$ ed. New York: Wiley; 1974. 992 p.

21. Kim S, Nam G, Park H, Yoon H, Lee SH, Kim JS, et al. Effects of Doping with Al, Ga, and In on Structural and Optical Properties of $\mathrm{ZnO}$ Nanorods Grown by Hydrothermal Method. Bulletin of the Korean Chemical Society. 2013;34(4):1205-1211.
22. Huang H, Zhao Q, Hong K, Xu Q, Huang X. Optical and electrical properties of $\mathrm{N}$-doped $\mathrm{ZnO}$ heterojunction photodiode. Physica E: Low-dimensional Systems and Nanostructures. 2014;57:113-117.

23. Zhang JP, Zhang LD, Zhu LQ, Zhang Y, Liu M, Wang XJ, et al. Characterization of $\mathrm{ZnO}: \mathrm{N}$ films prepared by annealing sputtered zinc oxynitride films at different temperatures. Journal of Applied Physics. 2007;102(11):114903.

24. Özgür Ü, Alivov YI, Liu C, Teke A, Reshchikov MA, Doğan S, et al. A comprehensive review of $\mathrm{ZnO}$ materials and devices. Journal of Applied Physics. 2005;98(4):041301.

25. Laidani N, Anderle M, Canteri R, Elia L, Luches A, Martino $\mathrm{M}$, et al. Structural and compositional study of B-C-N films produced by laser ablation of $\mathrm{B}_{4} \mathrm{C}$ targets in $\mathrm{N}_{2}$ atmosphere. Applied Surface Science. 2000;157(3):135-144.

26. Shinde SS, Shinde PS, Oh YW, Haranath D, Bhosale CH, Rajpure KY. Investigation of structural, optical and luminescent properties of sprayed N-doped zinc oxide thin films. Journal of Analytical and Applied Pyrolysis. 2012;97:181-188.

27. Ganjoo A, Golovchak R. Computer program PARAV for calculating optical constants of thin films and bulk materials: Case study of amorphous semiconductors. Journal of Optoelectronics and Advanced Materials. 2008;10(6):1328-1332.

28. Ohta Y, Haga Y, Abe Y. Crystallographic features of $\mathrm{ZnO}$ single crystals. Japanese Journal of Applied Physics. 1997;36:L1040-L1042.

29. Dhara S, Giri PK. Stable p-type conductivity and enhanced photoconductivity from nitrogen-doped annealed $\mathrm{ZnO}$ thin film. Thin Solid Films. 2012;520(15):5000-5006.

30. Yan Z, Song ZT, Liu WL, Wan Q, Zhang FM, Feng SL. Optical and electrical properties of p-type zinc oxide thin films synthesized by ion beam assisted deposition. Thin Solid Films. 2005;492(1-2):203-206. 